\title{
Multi-Stage Filter Designs for a Gasifier System
}

\author{
Sunil Kumar, Amit Kumar, O.P. Singh
}

\begin{abstract}
Most of the previous investigations on flow control devices have been reported on single-stage perforated plate with variable porosity and circular holes. This is the reason that functional relationships for pressure loss coefficient or Euler number (Eu) variation reported earlier are a strong function of porosity. In this paper, multi-stage filter design with constant porosity has been investigated using an experimentally validated numerical model. Several researchers have worked on the design of the producer gas cleaning system by using different filter materials such as electrostatic precipitators, wet scrubber, ceramics, fabric, and sand bed separately. However, these methods are inefficient in the final stages of the gas purification. Hence, multi-stage filters designs are conceived and investigated. Effect on pressure loss coefficient variation has been investigated for different hole geometry having same porosity with multiple filters. In a first, four new correlations has been developed for Eu variation as function of number of filters and different hole shapes. The Eu variation has the form: $E u=a(N)^{b}\left(t / d_{h}\right)^{c}$ where $N$ is the number of filters, $a, b$ and $c$ are constants whose value depend on the type of hole geometry. The prediction from correlation agrees within $4 \%$ accuracy with the numerical data
\end{abstract}

Keywords :Computational Fluid Dynamics, Filtration unit, Gasifier system, Porosity, Pressure loss coefficient

\section{INTRODUCTION}

Perforated plates are generally used in pressurised systems to control the pressure and regulate the flow such as high-pressure water filtering devices. They are also used for removing swirl effect of the flow, to make flow uniform or used for preventing cavitation phenomena for safe operating conditions [1]-[4]. The perforated plates used in various applications have been extensively investigatedin the scientific literature. Most of the previous investigations are focused on single stage designs with a focus on their functionality as pressure regulator and flow conditioners [5]-[8]. However, there are other applications where multi-stage filter designs are preferred such as cleaning of tar and ash particles in gasifier systems for biomass conversion into useful fuels. [9]-[12].

Biomass is a promising energy source for variation applications. To utilized biomass as a fuel, there are three different processes that are used for biomass energy conversion: gasification, pyrolysis, and direct combustion. Gasification is the process in which the solid biomass material is converted into the combustible gas through several thermochemical reactions is called producer gas. Producer gas having tar and ash particles that adversely affect the operation and performance of the engine, therefore, it is necessary to remove the tar and ash particles before it is used as a fuel to run the internal combustion (IC) engine [10], [13], [14]. To meet the needs of the power generating unit such as IC engine, the syngas should be appropriately cleaned from fixed bed reactors before feeding to the running engine. Apart from clean fuel, engine needs adequate fuel pressure for better engine efficiency. Filtration system plays a serious role for cleaning the producer gas in order to use the producer gas as a fuel for IC engine. Different types of filtration system are used for cleaning the tar as well as dust particles [9]-[12].

Several researchers have worked on the design of the producer gas cleaning system by using different filter materials such as electrostatic precipitators, wet scrubber, ceramics, fabric, and sand bed separately [11], [12]. It has been observed that some non-soluble impurities still remain in the final phases of filtration which goes into the engine. This effects the engine performance. Clearly, there is a need to develop a filtration system which deals with last phase of the filtration processes. Such filter unit performed two important functions. First, it filters very fine particles and second, regulate the engine intake pressure.

In this research work, a novel multi-stage filtration system has been investigated for regulating the pressure with minimum losses in the system. In the filter design, majority of the previous works are focused on single stage multi-hole circular hole designs [8], [15]. When no cavitation occurs, the pressure loss coefficient or Euler number $(\mathrm{Eu})$ in non-dimensional form plays an important factor in the perforated plate designs which is a function of Reynolds number, ratio of open area to overall pipe cross-section called porosity $(\beta)$, thickness ratio $\left(t / d_{h}\right)$, friction factor $(\lambda)$ of the holes, number of holes $\left(\mathrm{n}_{\mathrm{h}}\right)$, pitch $(\mathrm{P})$, contraction coefficient of the holes $(\mathrm{Cc})$ among other parameters [15]. Here, $t$ is the plate thickness and $d_{h}$ is the hole diameter. Since the losses are also affected by the friction factor $\lambda$, however, losses are a very weak function of $\lambda$ and neglected in such studies [8]. Most of the expressions reported for the pressure loss coefficient Eu are a strong function of porosity as shown in the Table I.

Revised Manuscript Received on November 19, 2019

* Correspondence Author

Sunil Kumar, Department of Mechanical Engineering, Indian Institute of Technology (BHU), Varanasi, India. Email: sunilkumar.rs.mec13@itbhu.ac.in

Amit Kumar, Department of Mechanical Engineering, Indian Institute of Technology (BHU), Varanasi, India. Email: amitk.rs.mec15@itbhu.ac.in

O. P. Singh ${ }^{*}$, Department of Mechanical Engineering, Indian Institute of Technology (BHU), Varanasi, India. Email: opsingh.mec@itbhu.ac.in 


\section{Multi-Stage Filter Designs for a Gasifier System}

Table I. Various correlations for Eu variation in perforated plates as a function of porosity.

\begin{tabular}{|c|c|c|}
\hline Reference & Expression & Validity range \\
\hline [1] & $\mathrm{Eu}=\left[\frac{\sqrt{1-\beta^{4}\left(1-C^{2}\right)}}{C \beta^{2}}-1\right]^{2}$ & $0.10<\beta<0.75$ \\
\hline [15] & $\begin{array}{l}\mathrm{Eu}=P_{m}\left(\beta^{-4.448}-1\right) \mathrm{P}_{m}=160.325\left(71.467 \beta^{4}-\right. \\
\left.100.300 \beta^{3}+52.021 \beta^{2}-11.801 \beta+1\right)\end{array}$ & $0.25 \leq \beta \leq 0.45$ \\
\hline [20] & $\begin{array}{l}\mathrm{Eu} \\
=\frac{0.5\left(1-\beta^{2}\right)+\tau\left(1-\beta^{2}\right)^{1.5}+\left(1-\beta^{2}\right)^{2}+\lambda t / d_{h}}{\beta^{4}}\end{array}$ & $R e_{h}>10^{5} t / d_{h}>0.015$ \\
\hline [21] & $\begin{array}{l}\mathrm{Eu}=\left[2.9-3.79\left(\mathrm{t} / d_{h}\right) \beta^{0.4}+1.79\left(t / d_{h}\right)^{2} \beta^{0.8}\right] K_{L A}, \\
K_{L A}=1-\frac{2}{\beta^{2}}+\frac{2}{\beta^{4}}\left(1-\frac{1}{C_{C}}+\frac{1}{2 C_{C}^{2}}\right) \\
\mathrm{Eu}=\left[0.876+0.069\left(\mathrm{t} / d_{h}\right) \beta^{0.4}\right] K_{L A}\end{array}$ & $\begin{array}{l}\left(t / d_{h}\right) \beta^{0.4}<0.9 \\
\left(t / d_{h}\right) \beta^{0.4}>0.9\end{array}$ \\
\hline [22] & $\begin{aligned} & \mathrm{Eu}=\frac{C_{0}\left(1-C_{C} \beta^{2}\right)^{2}}{C_{C}^{2} \beta^{4}}, \quad C_{C}=0.72 \\
& C_{0}=0.5+\frac{0.178}{4\left(t / d_{h}\right)^{2}+0.355} \\
& C_{C}=0.596+0.0031 e^{\beta / 0.206}\end{aligned}$ & $0.1<t / d_{h}<3$ \\
\hline [23] & $\begin{array}{l}\mathrm{Eu}=K_{0} \beta^{-4} \lambda_{a} \\
\mathrm{Eu}=K_{0.8} \beta^{-4} \lambda_{b}\end{array}$ & $\begin{array}{l}\mathrm{t} / \mathrm{d}_{\mathrm{h}}<0.8 \\
\mathrm{t} / d_{h}>0.8\end{array}$ \\
\hline [8] & $\mathrm{Eu}=0.67 \beta^{-2.24}$ & $0.064<\beta<0.331$ \\
\hline
\end{tabular}

Pressure loss coefficient is the measure of the dissipation characteristic of honeycomb substrate which is determined by the Euler number (Eu) [15].

$$
E u=\frac{P_{1}-P_{2}}{\frac{1}{2} \rho U^{2} m}
$$

$\mathrm{U}_{\mathrm{m}}$ is the mean upstream velocity, $\mathrm{P}_{1}$ and $\mathrm{P}_{2}$ are the pressure at up and downstream of filter unit. Fig. 1 shows the schematic diagram of multi-stage filter configuration. Reynolds number plays a significant role in pressure loss characterises; however, its definition is still contentious. Some authors [6], [7], [15], [16] define Reynolds number as, $R e_{p}=V_{p} D / v$, use pipe diameter as characteristics length and bulk mean velocity in pipe $V_{p}$. Other authors [17], [18] define Reynolds number as, $R e_{h}=V_{h} d_{h} / v$ where $V_{h}$ is the hole bulk mean velocity and $d_{h}$ is the hole diameter as shown in Fig. 1. Therefore, $\operatorname{Re}_{p}=\operatorname{Re}_{h} \sqrt{ } n_{h} \beta$. Some other authors [3], [19] define Reynolds numbers in terms of hole velocity but use pipe diameter as characteristics length as $R=V_{h} D / v$. Here $R$ is connected with $R e_{p}$ by the following relationship: $R e_{p}=\beta^{2}$ $R$. Irrespective of the definition of Reynolds number, the relationship between pressure loss coefficient $E u$ and Reynolds number $R e$ is qualitatively shown in Fig. 2 [1]. Variation of Eu can be classified into two different regions: ow Reynolds number region 1 where $E u$ is affected by

changes in Reynolds number and a self-similarity region 2 in which $E u$ remains constant with changing Reynolds number. A sudden increase in $E u$ is observed if the fluid undergoes cavitation. In this paper, pressure is low enough to investigate $E u$ variation, hence Reynolds number was kept constant.

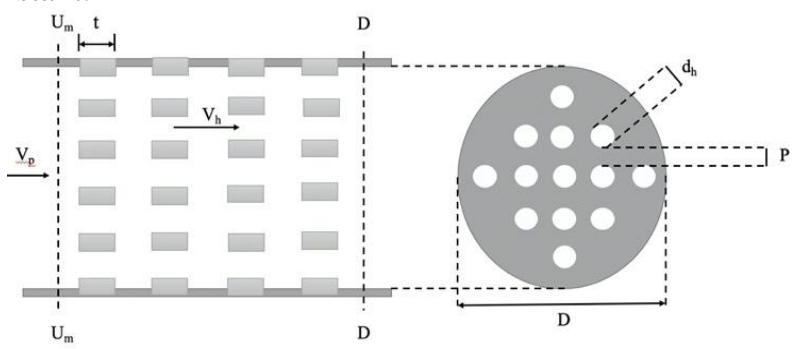

Fig. 1. Schematic diagram of a multi-stage (4-stage in this figure) filter design show the parameter details.

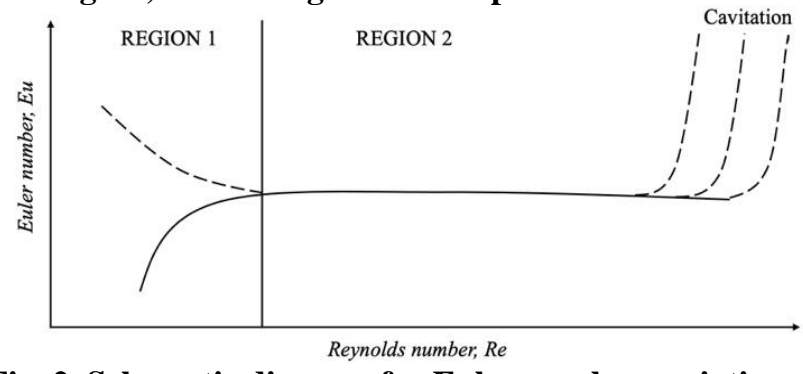

Fig. 2. Schematic diagram for Euler number variation vs. Reynolds number. In self-similarity region, $E u$ is independent of $R e$. 


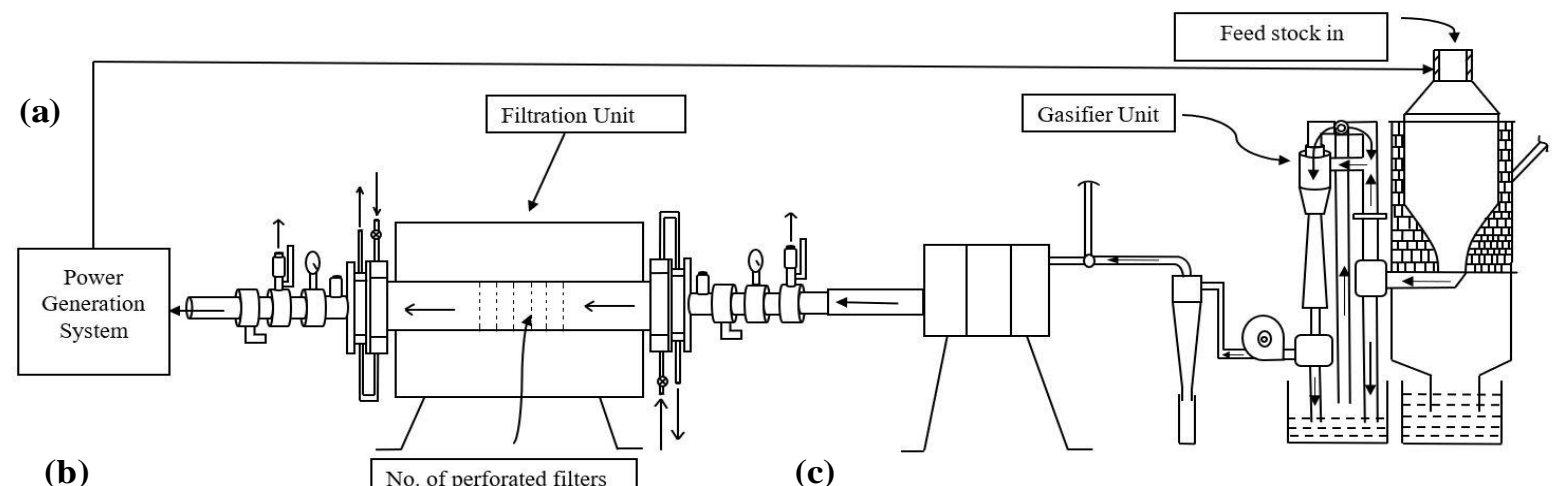

(b)

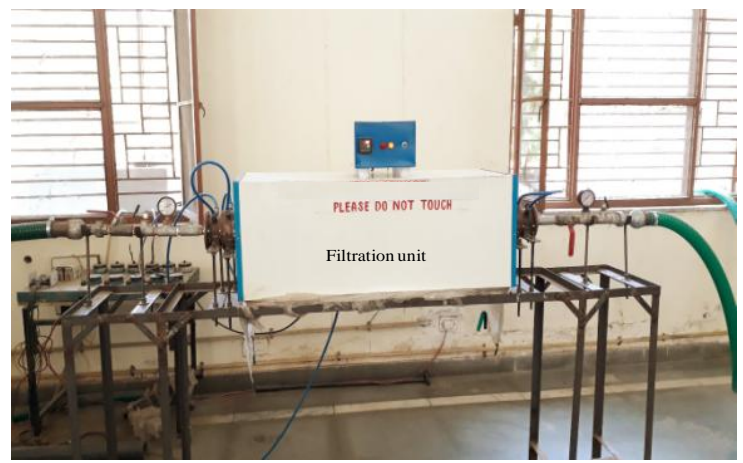

(c)

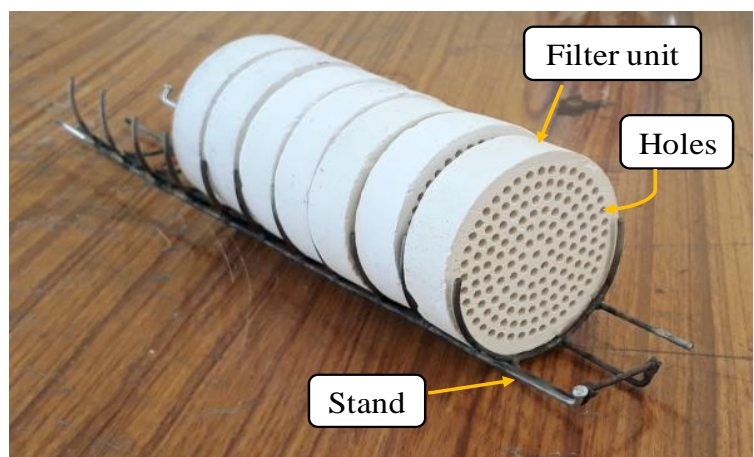

Fig. 3.(a) Schematic diagram of the experimental setup showing the various stages of filtration process of the gasification system. After the gasifier unit, contaminated gases are feed into the filtration unit after which it is feed to the power generation unit, (b) experimental setup of the filtration unit and (c) multi-stage filter design with circular holes.

An inhouse experimental setup was developed to study the effect of various multi-stage filter designs as shown in Fig. 3. Fig. 3(a) shows the schematic diagram of the entire setup while $3(b)$ is the photograph of filtration sub-unit and 3(c) is the photograph of the multi-stage filters that are placed inside the filtration unit. Note that the porosity of each filter is kept same. Filtered gases coming from the filtration unit was fed to the internal combustion engine or the power generation unit. For better filtration, more number of stages are preferable. However, higher pressure drop is a concern and higher pressure drop means that the power generating unit has to spend additional power to overcome high suction pressure. Initially, 7 stage filters were kept in a row having circular holes with $20 \mathrm{~mm}$ thickness of each filters (see Fig. $3(a))$ to investigate the engine performance. It was observed that measured power output was a strong function of filter designs and number of stages. Performing experiments with different designs of filters is a costly and time-consuming processes. For example, running one set of experiments for a given design of filters and stage requires about a weeks' time as it requires running the entire gasification system. Furthermore, changing the new filter designs from the filtration unit requires substantial time. Hence, the main motivation of this research is to develop suitable relationships or correlations of pressure loss coefficient with number of stages and thickness ratio using experimentally validated numerical model.

There are many questions that has not yet been answered in the scientific literature. The query that comes first is that what is the effect of different hole shapes of filter on pressure loss coefficient when porosity is kept constant? Hole shapes such are circular, rectangular, square and hexagonal are most common. Secondly, which hole shape performs better i.e. which shape exhibit lower pressure loss coefficients when porosity is kept constant? It is observed from the literature (also see Table I) that expression for pressure loss coefficient with constant porosity is scarce. Further, in case of filtration unit in gasifier system, multiple stage filtration is required where multiple filters are stacked side by side for effective filtration. It is to be noted when multiple perforated filters are placed inside the filtration unit (see Fig. 3), number of holes and hence, the porosity of each filters usually remains the same. Hence, the third query that needs to be addressed is the nature of correlation of Euler number variation with number of filters and thickness ratio when porosity remains constant. In this paper, a systematic analysis has performed to examine the effect of different hole shape and thickness on pressure loss coefficient variation. 


\section{Multi-Stage Filter Designs for a Gasifier System}

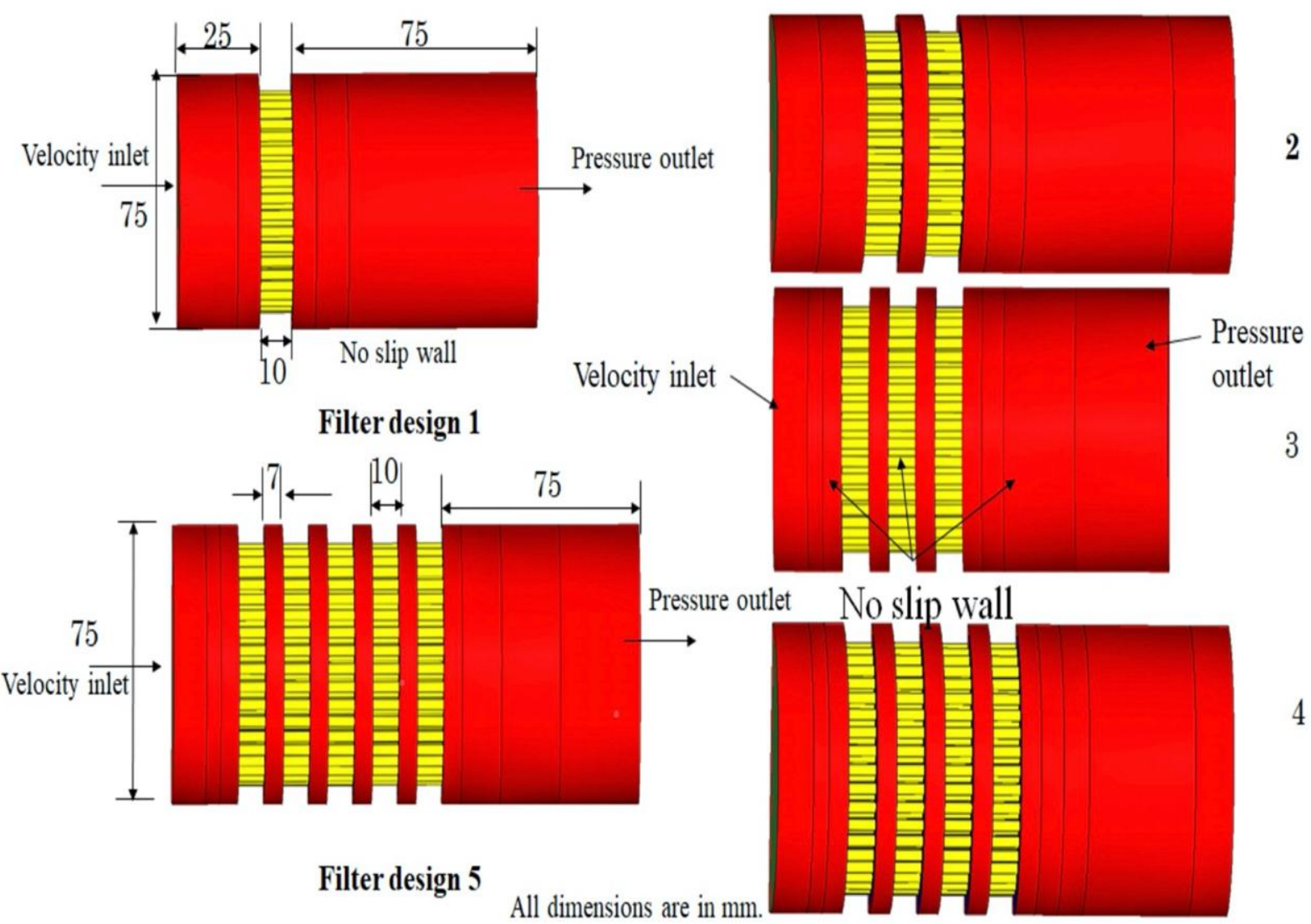

Fig. 4.Computational flow domain showing one stage filter system to 5 -stages. All dimensions are in $\mathrm{mm}$.

\section{COMPUTATIONAL FLUID DYNAMICS MODEL}

Numerical analysis was performed to know the performance of the filtration unit: an integral part of the downdraft gasifier system. Flow and pressure drop analysis have been investigated using CFD tool and the effect of honeycomb substrates consist of holes of different shapes like circular, square, equilateral, triangular and hexagonal was monitored on the effectiveness of filtration unit.

Fig. 4 shows the side view of the various fluid volume in the computational geometry containing different filters. Dimensions are in $\mathrm{mm}$. Length of inlet pipe is kept short while outlet was extended to stabilize the flow coming out from the filter unit. In filter housing system first filter always placed at a distance one-third of the diameter of the pipe $(D / 3)$ from the inlet and last filter was kept at a distance of the $D$ from the outlet. Outlet was kept far distance from the disturbances coming out the fluid after passing through the filters.

Fig. 5 shows the cross-sectional view of the different hole geometry of the honeycomb substrate. Different hole geometry of honeycomb substrate has been prepared to optimize the best hole geometry in order to reduce the pressure drop across the filtration unit when more number of substrates are kept in a row in the flow direction. Volume of each hole in the honeycomb structure has been kept same in all the geometry to make suitable performance comparison. Disposition of holes may play an important role in system performance. However, our investigations is focussed on symmetric holes placed on the plate. Effect of number of holes is significant only for lower value of porosity $\beta$ [1] where restrictions to flow is high. Hence, effect of number of holes has not been considered and it is kept constant in this study.

Details of the variable parameters and description have been prepared below in the tabulated form (Table II).

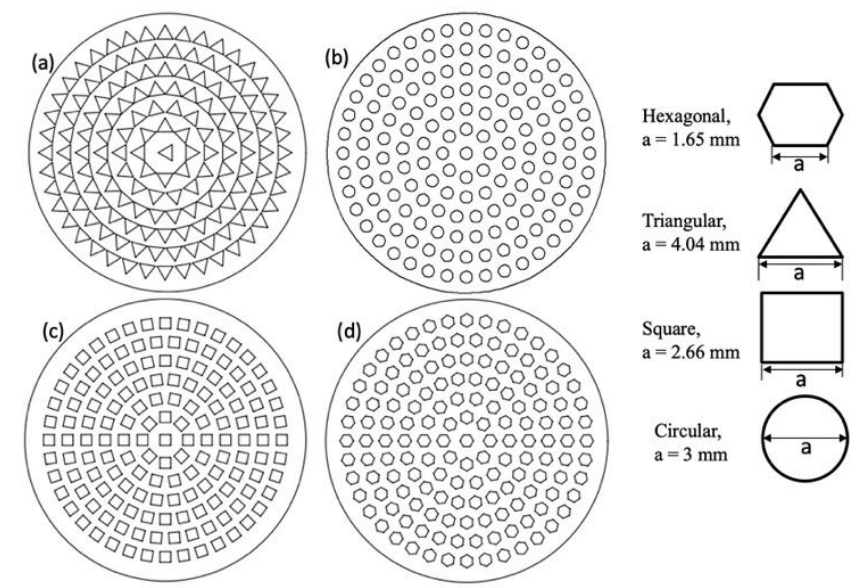

Fig. 5. Front view of the honeycomb substrate of hole geometry (a) triangular (b) circular(c) square and (d) hexagonal. Different hole was obtained (shownright) while volume was kept constant.

\section{A. Mesh Generation of Perforated Filters}

The unstructured mesh was chosen to mesh the flow domain. Fine mesh has been

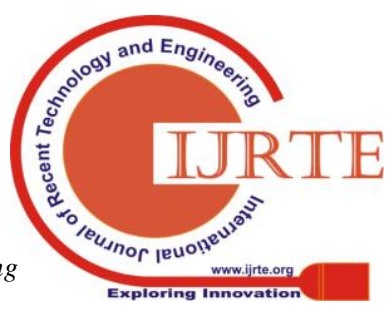


created in filters and its near zone to capture the actual flow different shape of perforated design has been kept same. behaviour. Note that porosity and number of holes for

Table- II: Details of meshing of perforated plates with different hole geometry.

\begin{tabular}{|c|c|c|}
\hline $\begin{array}{l}\text { Shape of } \\
\text { perforation }\end{array}$ & $\begin{array}{l}\text { Front view of } \\
\text { perforated filter } \\
\text { (substrate) }\end{array}$ & $\begin{array}{l}\text { Mesh scene of pipe } \\
\text { with perforated filter }\end{array}$ \\
\hline Circular & & \\
\hline Rectangular & & \\
\hline Triangular & & \\
\hline Hexagonal & & \\
\hline
\end{tabular}

\section{B. Governing Equation}

Three-dimensional geometry was used in all the cases. Since the flow was in turbulent regime, finite volume method with $\mathrm{k}-\varepsilon$ turbulent model was used. Coupled velocity and pressure fields are solved using SIMPLE (semi-implicit method for pressure linked equations) algorithm. Second order upwind scheme was used for special discretization. Convergence criteria for continuity and momentum equation was set to the order of $10^{-4}$. The flow phenomena through the honeycomb substrate was studied using the governing equations such as continuity equation, momentum equation, transport equation for kinetic energy $(\mathrm{k})$ and transport equation for energy dissipation ( $(\varepsilon)$ for the present analysis.

- Continuity equation

$\frac{\partial}{\partial \mathrm{x}_{\mathrm{i}}}\left(\rho \mathrm{u}_{\mathrm{i}}\right)=0$

\section{- Momentum equation}

$\frac{\partial}{\partial \mathrm{x}_{\mathrm{i}}}\left(\rho \mathrm{u}_{\mathrm{i}} \mathrm{u}_{\mathrm{j}}\right)=-\frac{\partial \mathrm{p}}{\partial \mathrm{x}_{\mathrm{i}}}+\frac{\partial}{\partial \mathrm{x}_{\mathrm{j}}}\left[\mu\left(\frac{\partial \mathrm{u}_{\mathrm{i}}}{\partial \mathrm{x}_{\mathrm{j}}}+\frac{\partial \mathrm{u}_{\mathrm{j}}}{\partial \mathrm{x}_{\mathrm{i}}}\right)\right]+$

$\frac{\partial}{\partial \mathrm{x}_{\mathrm{j}}}\left(-\rho \overline{\mathrm{u}_{1}^{\prime} \mathrm{u}_{\mathrm{j}}^{\prime}}\right)$

Equation (2) and (3) is also called theReynolds-Averaged Navier-Stokes (RANS) equations [22],[23]. Additional terms $-\rho \vec{u}_{i} \vec{u}_{j}$ in (3), represents the effects of turbulence. These Reynolds stresses, $-\rho{\overrightarrow{u_{i}}}_{{ }_{i} u_{j}}^{\prime}$ must be modelled in order to close(3). A common method employs the Boussinesq hypothesis to relate the Reynolds stresses with the mean velocity gradients:

$$
-\rho \overrightarrow{u_{i}^{\prime} u_{j}^{\prime}}=\mu_{t}\left(\frac{\partial u_{i}}{\partial x_{j}}+\frac{\partial u_{j}}{\partial x_{i}}\right)
$$

The $\mathrm{k}$ and $\varepsilon$ presents realizable transports in the equation (5) and (6) respectively [24].

\section{- $\quad$ Transport equation for kinetic energy $(k)$ :}

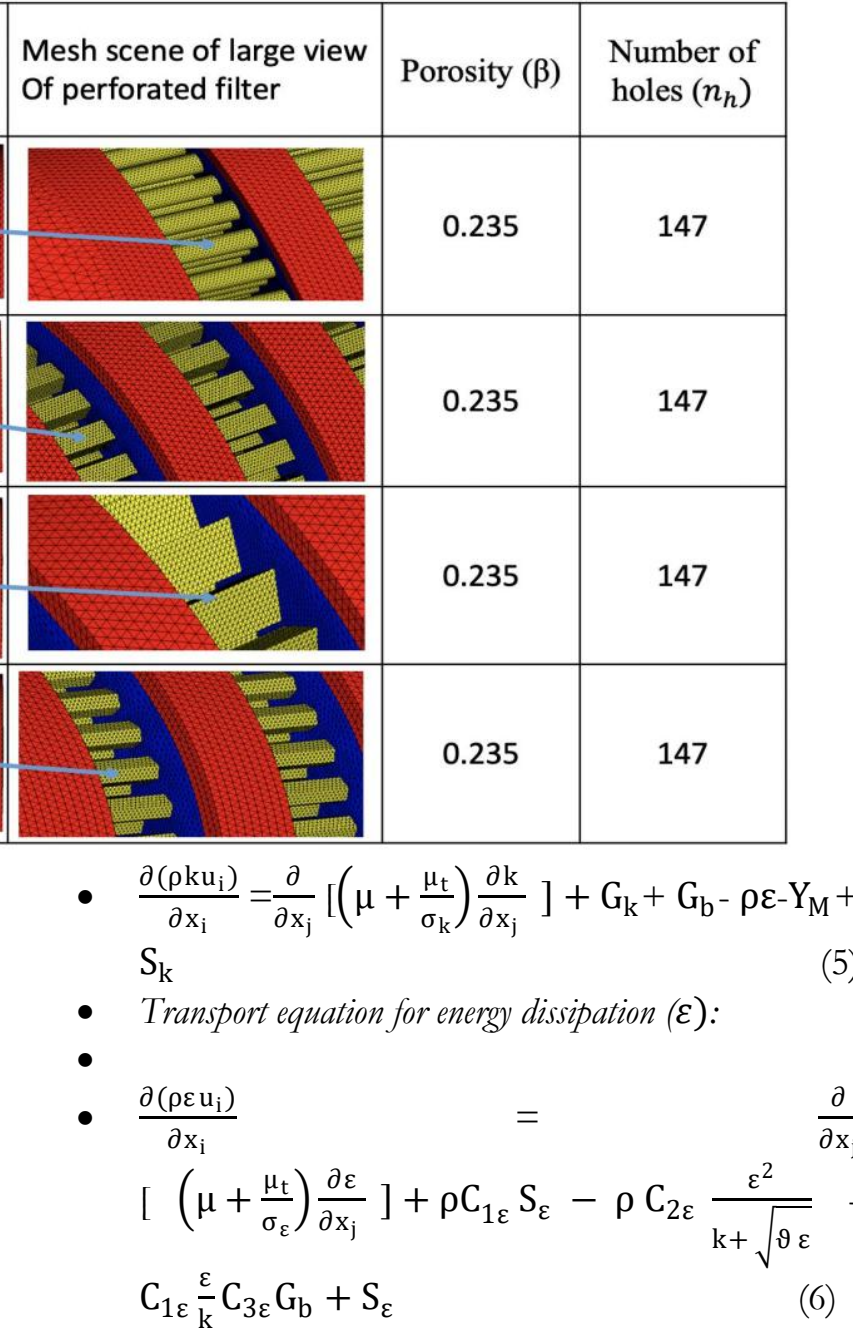

- where,

- $\mu_{t}=\rho C_{\mu} \frac{k^{2}}{\varepsilon}, G_{k}=\mu_{t} S^{2}, Y_{M}=\frac{C_{M} k \varepsilon}{C^{2}}$

- $G_{b}=-\rho{\overline{u_{i}^{\prime}}}_{{ }^{\prime} u_{j}^{\prime}} \frac{\partial\left(u_{j}\right)}{\partial x_{i}}$

- The Reynolds stress tensor, $R_{i j}$ and the modulus of the mean rate-of-strain tensor $\mathrm{S}$ are defined as:

- $R_{i j}=-\rho \overline{u_{i}^{\prime} u_{j}^{\prime}}, S=\sqrt{2 S_{i j} S_{i j}}$

- where, $C_{1 \varepsilon}, C_{2 \varepsilon}, C_{3 \varepsilon}, C_{M}, \mathrm{C}$ and $C_{\mu}$ are turbulence constants given as $C_{1 \varepsilon}=1.44, C_{2 \varepsilon}$ $=1.92, C_{3 \varepsilon}=-0.33, C_{M}=1.998, \mathrm{C}=1.88, C_{\mu}$ $=0.09, \sigma_{k}=1.0, \sigma_{\varepsilon}=1.3$.

\section{Boundary conditions}

The boundary conditions are chosen as velocity inlet for entry of air in the computational domain, pressure outlet for the exit of air from the computational domain. The boundary condition for all the other surfaces is selected as stationary wall with no-slip condition. The thermo-physical properties of air assumed to be constant. 
Values used in the model are: density, $\rho=1.184 \mathrm{~kg} / \mathrm{m}^{3}$, Prandtl number, $\operatorname{Pr}=0.71$, specific heat $C_{p}=1003.62 \mathrm{~J} / \mathrm{kgK}$ and viscosity, $\mu=1.857 \times 10^{-5} \mathrm{Ns} / \mathrm{m}^{2}$.

\section{Grid Independence Test}

To obtain CFD results that are independent of grid resolution [10] the grid independence test was performed by gradually increasing the number of mesh cells of the filtration unit when the number of filters in the computational domain increases to obtain different grid densities. The number of mesh cells for square honeycomb substrate of $5 \mathrm{~mm}$ thickness for one, two, three and four filters was 603873, 628873, 638873,643873 and the Euler number for the same was 46.8 , $48.0,49.0$ and 49.5 respectively. The percentage reduction in the Euler number is $2.56 \%, 2.0 \%$ and $1 \%$ respectively. There is very less variation in the percentage reduction in Euler number, not more than $1 \%$, for the mesh cell densities of 638873 and 643873 . Hence for the simulation study, the optimum mesh cell density was selected with 638873 cells in order to minimize the computational time as well as lesser memory storage.

Table- III: Values of Euler number obtained from experimental and computational model.

\begin{tabular}{|c|c|c|c|c|c|c|}
\hline $\begin{array}{l}\text { Reynolds } \\
\text { number }\end{array}$ & Velocity & $\begin{array}{c}\text { Experimental } \\
\text { Euler } \\
\text { number }\end{array}$ & $\begin{array}{c}\text { CFD } \\
\text { Euler } \\
\text { number }\end{array}$ & $\%$ error & $\begin{array}{l}\text { Number } \\
\text { of holes }\end{array}$ & $\begin{array}{c}\text { Porosity } \\
\text { (及) }\end{array}$ \\
\hline 2500 & 1.472 & 52 & 48.217 & -7.274 & \multirow[t]{6}{*}{$\overline{13}$} & \multirow[t]{6}{*}{0.165} \\
\hline 3100 & 1.826 & 50 & 47.596 & -4.808 & & \\
\hline 3700 & 2.179 & 49 & 47.2159 & -3.641 & & \\
\hline 4800 & 2.827 & 47 & 46.8 & -0.213 & & \\
\hline 5600 & 3.298 & 46 & 47.148 & 2.495 & & \\
\hline 6300 & 3.71 & 45 & 47.371 & 5.269 & & \\
\hline
\end{tabular}

\section{E. Experimental validation}

Fig. 6 shows the developed 3D geometry of single perforated plate reported, as in [8]. He reported the experimental results on Euler number variation with different hole distribution under given set of boundary conditions. We developed the same geometry and applied same boundary conditions, as reported in [8]. The comparison of Euler number $(E u)$ variation with Reynolds number from experimental and current model is shown in Table III. It can be seen that the model predicts relatively close values of Euler number variations with the experimental data. It can be said the developed model mimics the experimental conditions and hence, the model is validated.

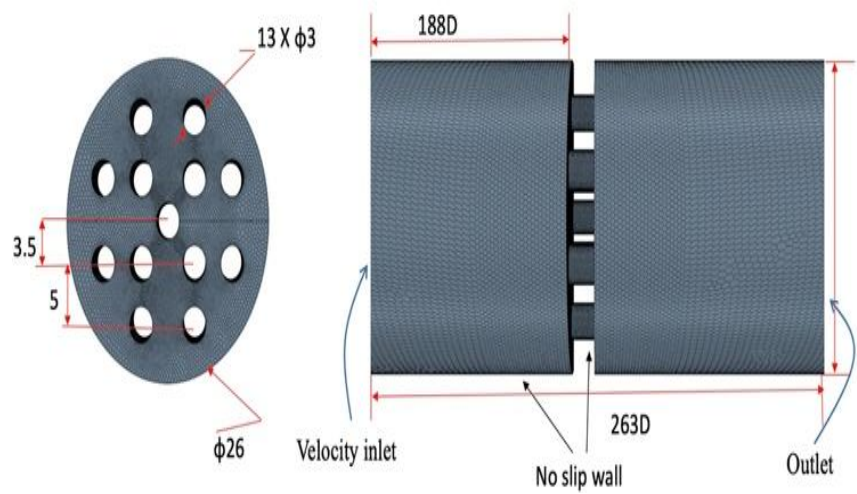

Fig. 6. Geometrical parameters of experimental setup, as in [8]. All dimensions are in millimeters.

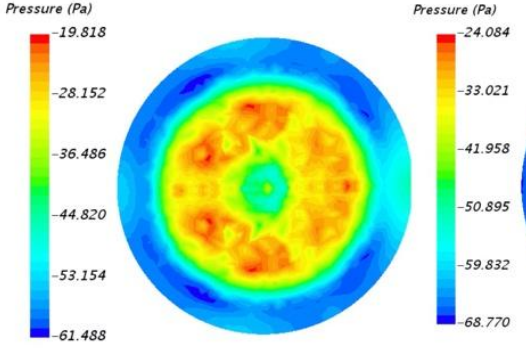

(a) Filter with equilateral triangle hole

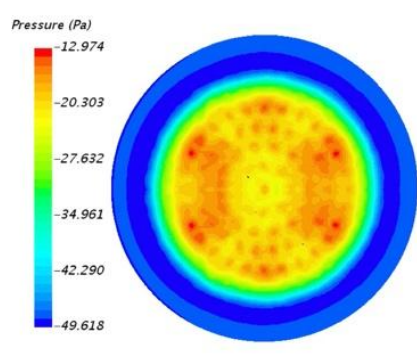

(c) Filter with square hole

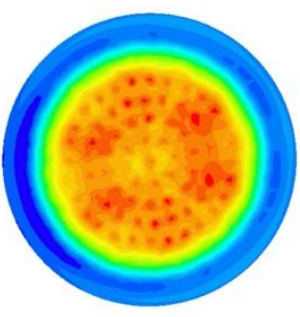

(b) Filter with circular hole
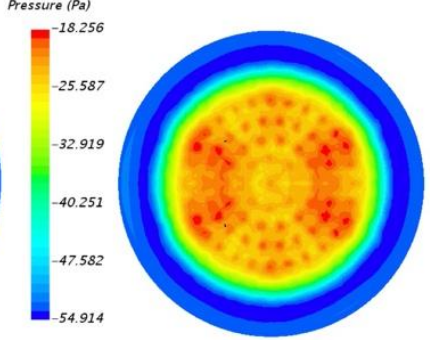

(d) Filter with hexagonal hole
Fig. 7. Pressure contours at a cross section for different designs of filter holes. Notice that triangular hole shows highly non-uniform pressure distributions.

\section{RESULT AND DISCUSSION}

Resultsobtained from developed experimental and numerical model are discussed below. It is to be mentioned here that Eu variation represent the data in self-similarity region where the effect of Reynolds number is insignificant (see Fig. 2) and porosity of the filter system is constant

\section{A. Velocity and pressure contours}

Fig. 7 shows the pressure contours at a cross section for different type of type filters. Range of pressure variations has been shown in the legend. It is work noting that square hole 
shows lowest pressure drop of about $36 \mathrm{~Pa}$ whereas circular holes show $44.67 \mathrm{~Pa}$ i.e. square holes show about $22 \%$ less pressure drop. Further, pressure variations are uniform across the square hole filter, which is a desirable filter design criteria. Usually, circular hole filters are expected to perform better than square hole filter. We performed a separate set of simulations for filters with only one hole: circulars and square (results not shown). It was observed that circular hole shows lower pressure drop than square hole. However, filters with multiple square hole shows better hydraulic performance. On further investigation, it was observed that multiple circular holes allow intense mixing downstream in comparison to square hole and hence,filter with square holes show less pressure drop. A lower pressure drop manifests into higher velocities across the filter. This is clearly seen in the velocity contour plot shown in Fig. 8. Though the legend of triangular hole shows highest velocity, it is just at a location. Its average velocity is much more lower than square filter design.

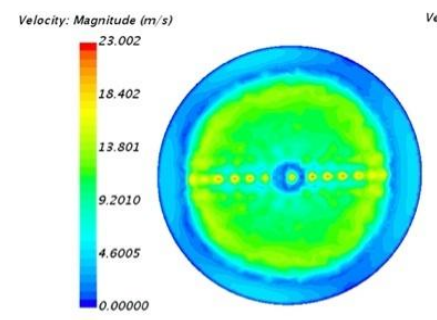

(a) Filter with equilateral triangle hole
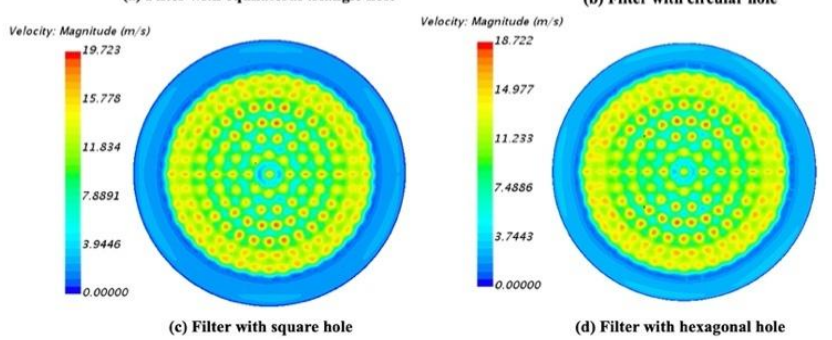

Fig. 8. Velocity contours at a cross section for different hole geometry. The corresponding pressure contours are shown in Fig. 7.

\section{B. Effect of single honeycomb substrate for different hole geometry}

Fig.9 (a) and (b) show the variation of static pressure along the axial distance in the duct for a single filter with different shape (circular, hexagonal, square and equilateral triangle) of perforation for fixed value of porosity $(\beta=0.235)$ and relative thickness $\left(t / d_{h}=1.67\right.$ and 3.33) of filters. It is found that the maximum and minimum pressure drop occur across the filter with equilateral triangular and hexagonal perforation shape. The loss of static pressure is mainly due to formation of boundary layer and enhanced mixing downstream of the filters. Consequently, increase of velocity of fluid in the core region was observed. Therefore, static pressure decreases continuously and reach minimum at exit of the filter. The static pressure away from the wall and perforation surfaces in the hole fall due to the reduction of the air passage. In spite of that, static pressure rises on the wall surface just before the filter.

Part of the pressure regains when air passes out of the filter as a result of the conversion of the dynamic head to static head.

Moreover, in downstream direction, the pressure distribution again comes down due to wall friction. It can also be seen that at any cross-section in the inlet or outlet channel, the static pressure distribution is uniform. The variations in static pressure over the cross section occur only at a distance about 2D upstream and downstream of the filter. It is observed that pressure loss in the hexagonal hole is minimum while it is maximum for triangular hole. Moreover, pressure loss for square and circular hole geometry lies in the range between minimum and maximum. With increase in filter thickness (Fig. 8b), pressure on the upstream side increasesacross all the designs. However, filter with triangular holes shows higher sensitivity with filter thickness. Dynamic changes in the pressure values is reflected in the corresponding changes in the velocities along the axial distance as shown Fig. 9(c) and 9(d).
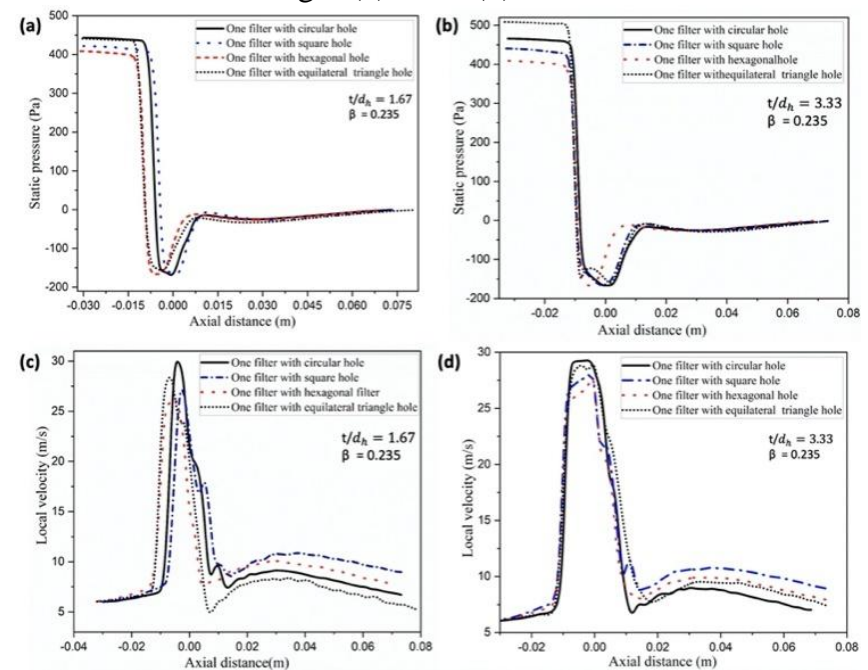

Fig. 9. Variation of static pressure with axial distance for single honeycomb substrate with thickness ratio (a) $t / d_{h}=$ 1.67, and $(b) t / d_{h}=3.33$. The corresponding variations in local velocity are shown in (c) and (d).

\section{Effect of multiple filters with different shape of perforation}

As stated earlier, multiple substrate helps filtration system better by filtering in stages. However, if the optimum number of the substrate is not put in the system, it might result in excessive pressure drop that may deteriorate the performance of the power generating unit. Since, circular and square filters exhibited better performance, now show the effect of putting multiple filters inside the chamber. Fig. 10 shows the static pressure variation for multiple circular holes in Fig. 10(a) and multiplesquareholes in Fig. 10(b). The corresponding variation in local velocity is shown in Fig. 10(c) and 10(d). It can be observed that pressure drop shows is strongly dependent on number of holes than with the thickness ratio. 

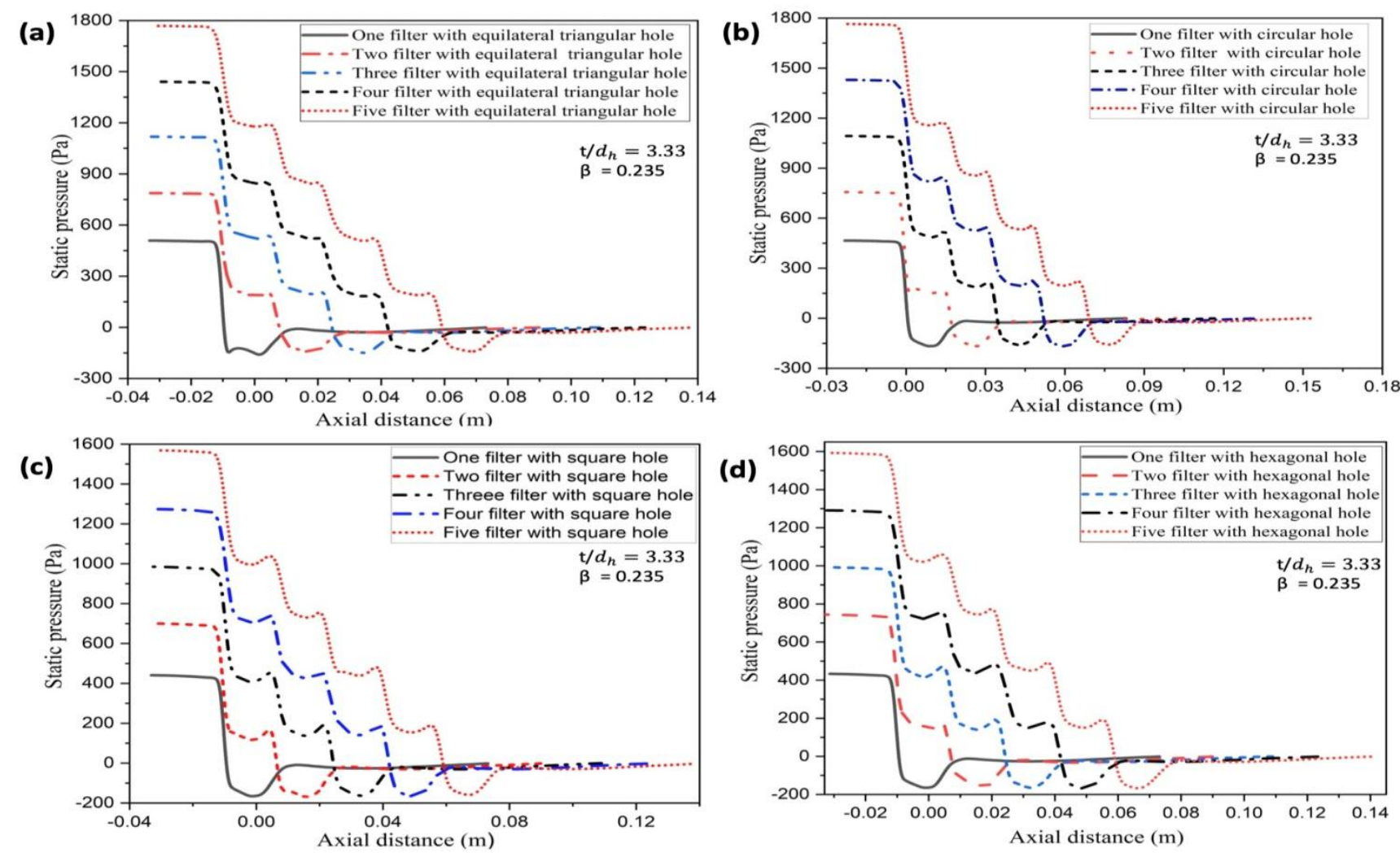

Fig. 10. Effect of multiple filters for a specific type of designs for a constant thickness ratio and porosity (both marked in the figure). (a) Static pressure variation for circular hole, (b)static pressure variation with square hole. The corresponding variations in local velocity is shown in (c)and (d).
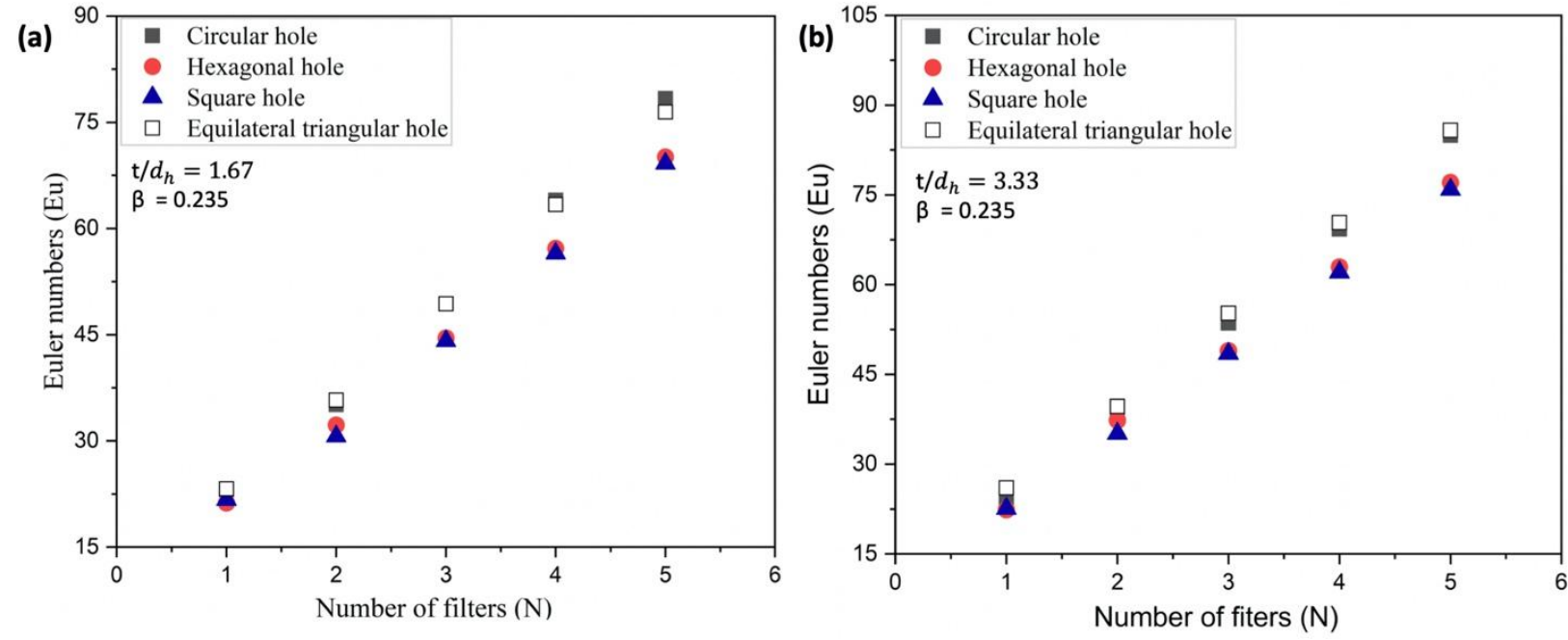

Fig. 11. Comparison of Euler number for different number of filters having circular, hexagonal, square and equilateral triangle hole for fixed value of relative thickness $(a) t / d_{h}=1.67,(b) t / d_{h}=3.33$ with porosity $\beta=0.235$ and $\operatorname{Re}=29110$ remain constant for all the cases.

Fig. 11 shows the variation of Euler number for different number of filters with different thickness. It confirms the previous observations (i.e. linear pressure drop) that Euler number increase linearly with increase the number of filters. It is due to the flow restriction increase with increase the number of filters. The maximum and minimum Euler number is obtained for equilateral triangular and square respectively. It can be seen that for different thickness, square filter performs better across the range of number filters used. The percentage increase of Euler number across the five filter (Fig. 11a) with the shape of perforation circular, hexagonal equilateral triangular with respect to square are $11.97 \%$, $1.54 \%$ and $13.02 \%$ respectively.

However, for larger thickness ratio (Fig. 11b), the percentage increase of Euler number are $13.29 \%, 1.30 \%$ and $10.54 \%$ respectively for circular, hexagonal equilateral triangular with respect to square filters.Further experimental tests were conducted with optimized number of filters by putting it in filtration unit shown in Fig. 2. Considering the scope of this paper, details of experimental observations will be presented 
somewhere else.

\section{CORRELATION DEVELOPMENT}

As discussed in previous sections, Euler number strongly depends on the number of filters $(\mathrm{N})$ and the geometrical parameter namely, the relative thickness of filter $\left(t / d_{h}\right)$ for constant porosity $(\beta)$. The functional relationship of Euler number in term of these parameters can be written as:

$$
E u=f\left(N, t / d_{h}\right)
$$

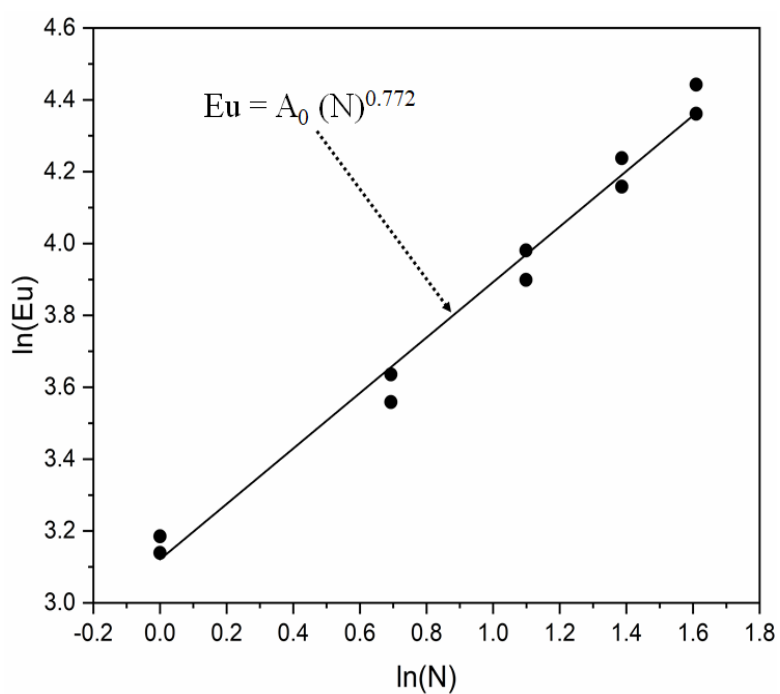

Fig. 12. A plot of $\ln (\mathrm{Eu})$ versus $\ln (\mathrm{N})$ for filtration unit with circular holes.

All the data points of Euler number obtained from numerical analysis of circular filter system were plotted against number of circular perforated filters $(\mathrm{N})$ as shown in Fig. 12.

$\mathrm{Eu}=\mathrm{A}_{0}(\mathrm{~N})^{0.772}(8)$

The coefficient $\mathrm{A}_{0}$ is a function of another operating parameter i.e. relative thickness of filter $\left(t / d_{h}\right)$. The regression analysis to fit these data points by a straight line can be represented by the following expression

$$
\ln \left(\frac{E u}{N^{0.772}}\right)=\ln \left(B_{0}\right)+B_{1} \ln \left(\frac{t}{d_{h}}\right)
$$

The equation (9) can be rearranged as

$$
\mathrm{Eu}=\mathrm{B}_{0}(\mathrm{~N})^{0.772}\left(\mathrm{t} / \mathrm{d}_{\mathrm{h}}\right)^{0.106}
$$

The value of the coefficients is obtained as $\mathrm{A}_{0}=22.66$ and $\mathrm{Bo}$ $=20.69$. Fig. 13 shows the comparison between Euler number obtained from the numerical data and those predicted by the developed correlation. The average absolute percentage deviations between numerical values and predicted values have been found to be $3.50 \%$. Simulations at other low Reynolds number were also performed. However, variation in $E u$ was not significantly high. A similar procedure has been adoptedto develop the correlation for the other perforation shape filters are listed in TableIV.

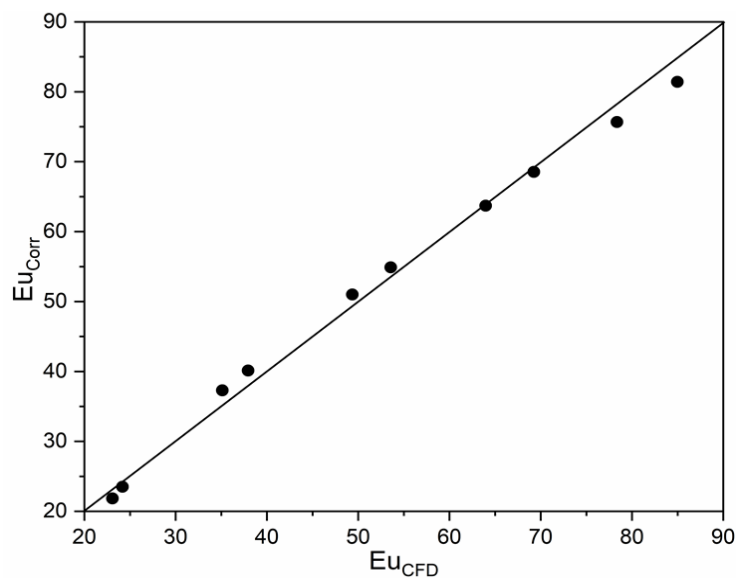

Fig. 13. Comparison of prediction data from the developed correlation with the CFD data. It can be seen

that the derived correlation predicts the data well.

Table- IV: Correlations for Euler number variation with number of filters $N$. Porosity $\beta=0.235, \mathrm{Re}=29110$ are kept constant for all the cases.

\begin{tabular}{|c|c|c|}
\hline $\begin{array}{c}\text { Perforati } \\
\text { on Shape }\end{array}$ & Correlation & $\begin{array}{c}\text { Absolute } \\
\text { Average } \\
\text { Percentage } \\
\text { Deviation }\end{array}$ \\
\hline $\begin{array}{c}\text { Circu } \\
\text { lar }\end{array}$ & $\mathrm{Eu}=20.69(\mathrm{~N})^{0.77}\left(\mathrm{t} / \mathrm{d}_{\mathrm{h}}\right)^{0.11}$ & $3.50 \%$. \\
\hline $\begin{array}{c}\text { Squar } \\
\mathrm{e}\end{array}$ & $\mathrm{Eu}=18.82(\mathrm{~N})^{0.74}\left(\mathrm{t} / \mathrm{d}_{\mathrm{h}}\right)^{0.13}$ & $3.97 \%$ \\
\hline $\begin{array}{c}\text { Hexa } \\
\text { gonal }\end{array}$ & $\mathrm{Eu}=18.8(\mathrm{~N})^{0.75}\left(\mathrm{t} / \mathrm{d}_{\mathrm{h}}\right)^{0.14}$ & $2.52 \%$ \\
\hline $\begin{array}{c}\text { Trian } \\
\text { gular }\end{array}$ & $\mathrm{Eu}=20.66(\mathrm{~N})^{0.74}\left(\mathrm{t} / \mathrm{d}_{\mathrm{h}}\right)^{0.16}$ & $3.10 \%$ \\
\hline
\end{tabular}

\section{CONCLUSION}

When multiple perforated plates are placed side by side to perform filtration in a gasifier system, porosity of each filters is usually kept constant keeping cost, ease of maintenance and manufacturing in mind. This paper deals with such scenarios to develop understanding of the filtration unit and effect of various hole shapes such as circular, square, triangular and hexagonal perforated filters has been investigated. Following are the main observations:

a) Square holes in the perforated filter performs better than other type of holes such a circular, triangular and hexagonal. However, a single circular hole shows lower pressure loss coefficient or Euler number variation compared to other type of filters.

b) For filtration unit with constant porosity, number of perforated plates plays a significant role in controlling overall pressure loss coefficient than thickness ratio.

c) Four new correlations are developed for perforation shapes with circular, square, triangular and hexagonal holes. The correlation has the form: $E u=a(N) b(t / d h) c$ where $\mathrm{a}, \mathrm{b}$ and $\mathrm{c}$ are constants.

d) The predicted values of Euler number agree within $4 \%$ accuracy with the numerical data. 


\section{Multi-Stage Filter Designs for a Gasifier System}

\section{NOMENCLATURES}

$c_{p} \quad$ Specific heat of air

$D \quad$ Diameter of pipe

$d_{h} \quad$ Diameter of substrate hole

$\mathrm{Eu} \quad$ Euler number

P Pitch

$U_{m} \quad$ Mean velocity of air

Re Reynolds number

$t \quad$ Thickness of filter

$\rho \quad$ Density of the fluid

\section{REFERENCES}

1. S.Malavasi, G. Messa, U. Fratino and A. Pagano, "On the pressure losses through perforated plates.'Flow Measurement and Instrumentation, vol. 28, 2012, pp. 57-66.

2. J. P. Tullis, "Hydraulics of pipelines-pumps, valves, cavitation, transients," New York: John Wiley and Sons. 1989.

3. G. Gan, and S. B.Riffat, "Pressure loss characteristics of orifice and perforated plates," Experimental Thermal and Fluid Science, vol.14 (2), 1997, pp. 160-165.

4. E. M. Laws, and A. K.Ouazzane, "A further investigation into flow conditioner design yielding compact installations for orifice plate flow metering. Flow Measurement and Instrumentation," vol. 6(3), 1995, pp. 187-199.

5. A. Erdal, "A numerical investigation of different parameters that affect the performance of a flow conditioner," Flow Measurement and Instrumentation, vol. 8(2), 1997, pp. 93-102.

6. S. Malavasi, S. Macchi, and E. Mereghetti, "Cavitation and dissipation efficiency of multi hole orifices," In: C.Z. Prague, I. Zolotarev, and J. Horacek, editors. Proceedings of the 9th international conference on flow-induced vibrations FIV2008. Prague: Institute of Thermomechanics Academy of Sciences of the Czech Republic. 581-586. 2008.

7. S. Malavasi, G. V. Messa, and S. Macchi, "The pressure loss coefficient through sharp-edged perforated plates," In: W. Farina, editor. Atti del XXXII Convegno Nazionale di Idraulica e CostruzioniIdrauliche. Dipt. of IIAA University of Palermo. 193. 2010.

8. E. Ozahi, "An analysis on the pressure loss through perforated plates at moderate Reynolds numbers in turbulent flow regime," Flow Measurement and Instrumentation, vol. 43, 2015, pp. 6-13.

9. P. Dokmaingam, R. S. Kempegowda, S. Assabumrungrat, and N. Laosiripojana, "System Efficiency Analysis of SOFC Coupling with Air, Mixed Air-Steam and Steam Gasification Fueled by Thailand Rice Husk,” Engineering Journal, vol. 21(4), 2017, pp. 95-110.

10. D. S. Mandwe, S. R. Gadge, A. K. Dubey, and V. P. Khambalkar, "Design and development of a $20 \mathrm{~kW}$ cleaning and cooling system for a wood-chip gasifier," Journal of Energy in Southern Africa, vol. 17(4), 2006, pp. 65-69.

11. R. Ramasamy, and M. K.Gounder, Performance of hybrid compact filter system in a down-draft gasifier: An experimental Performance of hybrid compact filter system in a down-draft gasifier: An experimental study, Journal of Renewable and Sustainable Energy, vol. 5, 2013.

12. T. Pongnam, and V.Plermkamon, "Improvement of Pulp and Paper Mill Industries Effluent Quality Using Bagasse Fly Ash,” Engineering Journal, vol. 22(4), 2018, pp. 13-22.

13. J. Delgado, M. P. Aznar, and J. Corella, "Biomass Gasification with Steam in Fluidized Bed: Effectiveness of $\mathrm{CaO}, \mathrm{MgO}$, and $\mathrm{CaO}-\mathrm{MgO}$ for Hot Raw Gas Cleaning," Industrial \& Engineering Chemistry Reserch, vol. 36(5), 1997, pp. 1535-1543.

14. P. Hasler, and T.Nussbaumer, "Gas cleaning for IC engine applications from fixed bed biomass gasification," Biomass and Bioenergy, vol. 16(6), 1999, pp. 385-395.

15. T. Zhao, J. Zhang, and L. Ma, "A general structural design methodology for multi-hole orifices and its experimental application," Journal of Mechanical Science and Technology, vol. 25(9), 2011, pp. 2237-2246.

16. U. Fratino, "Hydraulic and cavitation characteristics of multi hole orifices" In: Proceedings of the hydraulic machinery and system 20th IAHR symposium, 2000.

17. L. J. Weber, M. P. Cherian, M. E. Allen, and M. Muste, "Head loss characteristics for perforated plates and flat bar screens," Technical report. Iowa City (IA), USA: Iowa Institute of Hydraulic Engineering,
College of Engineering, University of Iowa. Mar. Report no. 411, 2000.

18. I. E. Idelcick, "Handbook of hydraulic resistance," 1986, Washington (DC), USA: Hemi- sphere.

19. G. J. Holt, D. Maynes, and J. Blotter, "Cavitation at sharp edge multi-hole baffle plates," In: Proceedings of the ASME 2011 International Mechanical Engineering Congress \& Exposition (IMECE), November 11-17, Denver, Colorado, USA, 2011.

20. D. S. Miller, "Internal flow system," (1990). Bedford, UK: Cranfield.

21. ESDU, 81039. "Flow of liquids. Pressure losses across orifice plates, perforated plates and thick orifice plates in ducts. Internal Flow and Physical Properties Group," 1981, Technical report, London, UK.

22. C. Suvanjumrat, "Implementation and Validation of OpenFOAM for Thermal Convection of Airflow," Engineering Journal, vol. 21(5), 2017. pp. 225-241.

23. P. Chaiwang, B. Chalermsinsuwan, and P. Piumsomboon, "Two-dimensional CFD simulation of reducing operating pressure effect on the system hydrodynamics in a downer reactor," Engineering Journal, vol. 21(2), 2017, pp. 133-149.

24. Z. Feng, Z. Long, and Q. Chen, Assessment of various CFD models for predicting airflow and pressure drop through pleated filter system, Building and Environment, vol. 75, 2014, pp. 132-141.

\section{AUTHORS PROFILE}

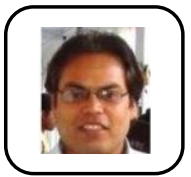

Sunil Kumarobtained his bachelor's degree from the Mandsaur Institute of Technology (MIT), Mandsaur in 2005. He then completed his Master's degree in Thermal and Fluid Engineering from Institute of Technology (BHU), Varanasi in 2009. He is currently pursuing a Ph.D. Varanasi,India degree at the Indian Institute of Technology (BHU),

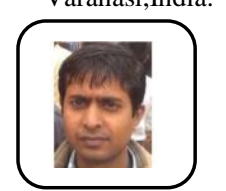

Amit Kumarreceived the bachelor's degree from Bhagalpur College of Engineering (BCE), Bhagalpur in 2014. He is currently pursuing a Ph.D. degree at the Indian Institute of Technology (BHU), Varanasi,India.

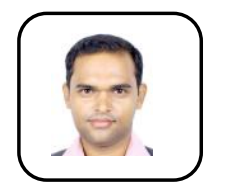

Dr. Om Prakash Singh works as Associate professor at IIT (BHU) in the department of Mechanical Engineering. His research interests are computational fluid dynamics, renewable energy, design and innovation. 